\title{
Mechanistic understanding on oxygen evolution reaction on $\gamma$-Fe0OH (010) under alkaline condition based on DFT computational study
}

\author{
Miru Tang, Qingfeng Ge* \\ Department of Chemistry and Biochemistry, Southern Illinois University, Carbondale, IL 62901, USA
}

\section{A R T I C L E I N F O}

\section{Article history:}

Received 30 November 2016

Accepted 26 December 2016

Published 5 September 2017

\section{Keywords:}

Water splitting

Oxygen evolution reaction

DFT + U

Iron oxyhydroxides

\begin{abstract}
A B S T R A C T
An efficient and economical oxygen evolution reaction (OER) catalyst is critical to the widespread application of solar energy to fuel conversion. Among many potential OER catalysts, the metal oxyhydroxides, especially $\mathrm{FeOOH}$, show promising OER reactivity. In the present work, we performed a DFT + U study of the OER mechanism on the $\gamma$-FeOOH (010) surface. In particular, we established the chemical potential of the $\mathrm{OH}^{-}$and hole pair and included the $\mathrm{OH}^{-}$anion in the reaction pathway, accounting to the alkaline conditions of anodic OER process. We then analyzed the OER pathways on the surface with $\mathrm{OH}-, \mathrm{O}$ - and Fe-terminations. On the surface with $\mathrm{OH}$ - and $\mathrm{O}$ - terminations, the $\mathrm{O}_{2}$ molecule could form from either $\mathrm{OH}$ reacting with the surface oxygen species $\left(-\mathrm{OH}^{*}\right.$ and $\left.-\mathrm{O}^{*}\right)$ or the combination of two surface oxygen species. On the Fe-terminated surface, $\mathrm{O}_{2}$ can only form by adsorbing $\mathrm{OH}$ on the Fe sites first. The potential-limiting step of the oxygen evolution with different surface terminations was determined by following the free-energy change of the elementary steps along each pathway. Our results show that oxygen formation requires recreating the surface $\mathrm{Fe}$ sites, and consequently, the condition that favors the partially exposed Fe sites will promote oxygen formation.
\end{abstract}

(C) 2017, Dalian Institute of Chemical Physics, Chinese Academy of Sciences. Published by Elsevier B.V. All rights reserved.

\section{Introduction}

The oxygen evolution reaction (OER) is involved in a number of energy conversion and storage technologies, including solar driven water splitting for hydrogen production and rechargeable metal-air batteries [1-4]. The OER, a four-electron oxidation reaction, is the limiting step of the entire water splitting process due to its slow kinetics $[5,6]$. Therefore, catalysts are needed to improve the kinetics of OER. The oxidative nature of the anode under the oxygen evolution conditions makes metal oxides the natural choices of the catalysts for OER. The anode catalysts based on $\mathrm{RuO}_{2}$ and $\mathrm{IrO}_{2}$ have been demonstrated to be effective for OER, showing low overpotentials at the high current density in the acidic electrolyte water electrolyzer [7-9]. However, the practical application of these materials has been hindered due to their high costs and low natural abundance.

Recently experimental studies demonstrated that the Bi$\mathrm{VO}_{4} / \mathrm{MOOH}$ (with $\mathrm{M}=\mathrm{Fe}, \mathrm{Ni}, \mathrm{Co}$ ) co-catalyst shows outstanding performance matching the traditional noble metal oxides-based photocatalyst $\left(\mathrm{IrO}_{2}, \mathrm{RuO}_{2}\right.$, etc.) for solar water splitting [10-13]. Those studies stimulated great interests in ex-

\footnotetext{
* Corresponding author. E-mail: qge@chem.siu.edu

This work was supported by the Chemical, Biological, Environmental, and Transport Systems (CBET) program of US National Science Foundation (CBET-1438440).

DOI: 10.1016/S1872-2067(17)62760-8 | http://www.sciencedirect.com/science/journal/18722067 | Chin. J. Catal., Vol. 38, No. 9, September 2017
} 
ploring the oxides/oxyhydroxides of the $3 d$ transition metals as catalysts for OER [14-24]. Man et al. [25] measured the overpotential for the OER of oxyhydroxides of several $3 d$ elements on $\mathrm{Pt}(111)$ as catalysts and reported an activity trend as $\mathrm{Ni}>\mathrm{Co}$ $>\mathrm{Fe}>\mathrm{Mn}$. Boettcher and coworkers [22,26,27] concluded that the most active structures are those where Fe is supported in a $\mathrm{Ni}$ or Co oxyhydroxide host. In such structures, Fe provides the active sites while the host provides the needed electrical conductance and surface area. Hybrid structures including nanotube arrays exhibit high electrocatalytic performance for OER [16].

Matsumoto and Sato [28] summarized various OER mechanisms in both acidic and alkaline conditions. Under acidic condition, the oxidation steps are characterized by the release of $\mathrm{H}^{+}+\mathrm{e}^{-}$pairs. Most theoretical studies of OER deal with the reaction under acidic condition by treating the oxidation steps as the release of the proton-electron pairs following the example of Rossmeisl et al. [29]. As such, the OER process on the metal oxides has been separated into four elementary steps, the water molecule first adsorbs on the surface of the catalyst, forming three oxygen-containing intermediates, including $\mathrm{OH}^{*}, \mathrm{O}^{*}$ and $\mathrm{OOH}^{*}$, in a stepwise process. For example, Man et al. [25] showed that the potential-limiting step of OER on $\mathrm{LaMnO}_{3}$ is the formation of the $\mathrm{OOH}^{*}$ species on the catalytic site. Chen et al. [30] showed that the first proton-coupled electron transfer of water oxidation on anatase $\mathrm{TiO}_{2}$ occurs sequentially with electron transfer following the proton transfer. Under the alkaline condition, on the other hand, the surface is expected to react with $\mathrm{OH}^{-}$to create a surface $\mathrm{OH}$ species, which will then undergo further reactions to form oxygen. Experimentally, the oxyhydroxides (MOOH) of $\mathrm{Fe}, \mathrm{Ni}$ and $\mathrm{Co}$ all show catalytic activity toward OER $[11,17,26]$ and $\mathrm{FeOOH}$ only shows significant OER activity under alkaline condition [31]. These oxyhydroxides contain intrinsically surface hydroxyl groups, which may play important roles in OER.

In the present study, we performed a comprehensive study of the possible OER intermediates on the three surface terminations of $\gamma$-FeOOH (010). This selection is based on previous experimental studies that demonstrated $\gamma$-FeOOH exhibiting higher water oxidation activity than $\alpha$-FeOOH [32,33]. In order to account for the alkaline condition of the anode in a typical alkaline water electrolyzer, we first established the chemical potential of the $\left(\mathrm{OH}^{-}+\mathrm{h}^{+}\right)$pair and then treated $\mathrm{OH}$ as a reactant in the elementary steps leading to oxygen formation.

\section{Computational method}

All calculations were performed using the Vienna Ab-Initio Simulation Package (VASP) code, an implementation of the first principles density functional theory (DFT) method with plane wave basis set and spin-polarized generalized gradient approximation [34,35]. In particular, we used the Perdew-Burke-Ernzerhof (PBE) functional [36] with an on-site Coulomb correction $\left(U_{\text {eff }}=5.0 \mathrm{eV}\right)$ [37]. The semicore $3 d$ state of $\mathrm{Fe}$ was treated as the valence state within the Projector-Augmented Wave (PAW) method [38].

The crystal structure of $\gamma$-FeOOH was built based on the

electron diffractometry data reported by Zhukhlistov [39]. The $\gamma$-FeOOH crystal is arranged into a layered structure and each layer consists of a double layer of Fe octahedra with the hydroxyl groups binding the layers through hydrogen bonding, as shown in Fig. 1. The (010) surface was modeled using a slab with a $\mathrm{p}(2 \times 2)$ cell in the surface direction and $10 \AA$ vacuum space between the slabs. Thus, the supercell has a dimension of $7.98 \AA \times 6.06 \AA$ × $15.81 \AA$. A $4 \times 3 \times 1$ K-point grid was used to sample the surface Brillion zone. Three terminations, including OH-, O-, and Fe-terminated surfaces (Fig. 1), were examined in turn in the present study.

\section{Results and discussion}

\subsection{Determination of the chemical potential of the $\left(\mathrm{OH}^{-}+h^{+}\right)$ pair}

Before presenting the DFT results of the elementary steps of OER, we first defined and determined the chemical potential of the $\left(\mathrm{OH}^{-}+\mathrm{h}^{+}\right)$. In the previous theoretical study of electrochemical hydrogen evolution and oxygen reduction reactions, Nörskov and coworkers defined the computational hydrogen electrode (CHE) as $1 / 2 \mathrm{H}_{2}(\mathrm{~g})=\mathrm{H}^{+}+\mathrm{e}^{-}[29,40]$. As such, the chemical potential of the proton-electron pair equals half of the chemical potential of hydrogen molecule at the standard state. Such a standard electrode works well under acidic condition where proton coupled electron transfer dominates the rate processes, as demonstrated in many previous studies [29,41-45]. On the other hand, the OER process on the metal oxyhydroxide-based catalysts is typically operated under basic conditions, sometimes very high alkaline concentrations. Under such a condition, using $\left(\mathrm{H}^{+}+\mathrm{e}^{-}\right)$is not likely to reflect the oxidative environment due to abundant $\mathrm{OH}^{-}$. Therefore, we developed a $\left(\mathrm{OH}^{-}+\mathrm{h}^{+}\right)$pair as the reactive species participating in the reaction. The chemical potential of the $\left(\mathrm{OH}^{-}+\mathrm{h}^{+}\right)$pair is defined on the basis of CHE by introducing $\mathrm{H}^{+}(\mathrm{aq})+\mathrm{OH}^{-}(\mathrm{aq}) \leftrightarrow$

Bulk

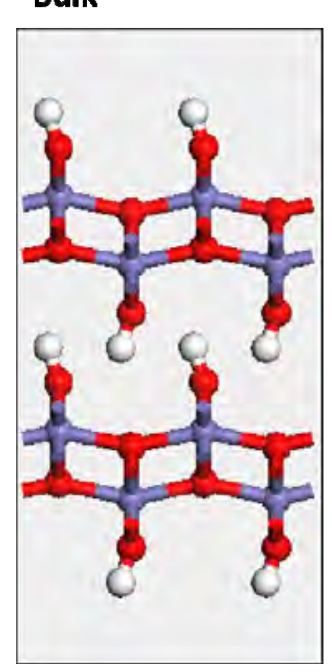

010

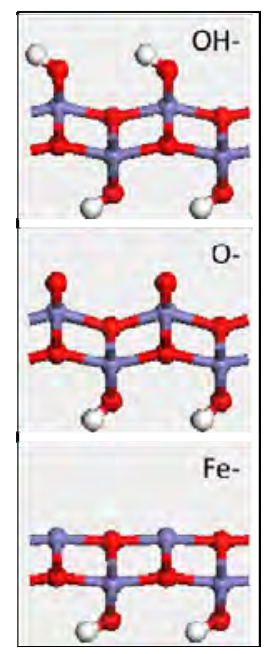

Fig. 1. Schematic structures of bulk FeOOH and the (010) surface with different terminations. Blue spheres represent the Fe atoms, red the 0 atoms and white the $\mathrm{H}$ atoms. 


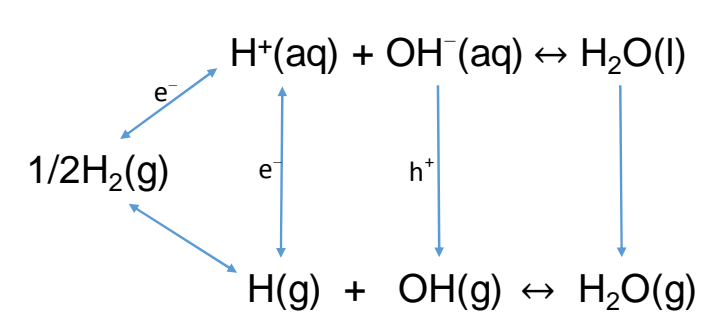

Fig. 2. The thermodynamics cycle used to determine the chemical potential of the $\left(\mathrm{OH}^{-}+\mathrm{h}^{+}\right)$pair.

$\mathrm{H}_{2} \mathrm{O}(\mathrm{l})$ and constructing the thermodynamic cycle shown in Fig. 2. The reaction free energies of each step under the standard condition can be calculated based on the available thermodynamic data. The calculation yielded a reaction free energy of $1.98 \mathrm{eV}$ for $\mathrm{OH}^{-}+\mathrm{h}^{+} \leftrightarrow \mathrm{OH}(\mathrm{g})$. Consequently, we used this value in combination with the DFT calculated energy of $\mathrm{OH}$, i.e. correcting the DFT calculated free energy change for all the steps involving the $\left(\mathrm{OH}^{-}+\mathrm{h}^{+}\right)$pair by adding $1.98 \mathrm{eV}$. We note that the value would be $2.32 \mathrm{eV}$ if DFT calculated free energies were used in calculation. In fact, the chemical potential of the $\mathrm{COH}^{-}+$ $\mathrm{h}^{+}$) pair will not only be applicable to the study of OER but also provide us to a tool to study other reactions under alkaline conditions.

\subsection{Relative stability of $\mathrm{FeOOH}(010)$ with different terminations}

The slab with OH-termination maintaning the stoichiometric ratio of $\mathrm{FeOOH}$ can be constructed from bulk FeOOH. The most relevant surface is expected to be the 0 -termination of $\mathrm{FeOOH}(010)$, especially in the aqueous environment. Previous DFT study indicated that the Fe-termination could dominate under water-poor conditions [46,47]. The free energy differences between the $\mathrm{OH}$ - and $\mathrm{O}$ - or Fe- terminated surface can be calculated based on the following reactions:

$$
\begin{gathered}
-\mathrm{Fe}^{*}+\left(\mathrm{OH}^{-}+\mathrm{h}^{+}\right) \rightarrow-\mathrm{OH}^{*} \\
\Delta G=\Sigma G_{\text {product }}-\Sigma G_{\text {reactant }}=-1.36 \mathrm{eV}+\mathrm{eU} \\
-\mathrm{Fe}^{*}+2\left(\mathrm{OH}^{-}+\mathrm{h}^{+}\right) \rightarrow \mathrm{H}_{2} \mathrm{O}+-\mathrm{O}^{*} \\
\Delta G=\Sigma G_{\text {product }}-\Sigma G_{\text {reactant }}=-0.23 \mathrm{eV}+\mathrm{eU}
\end{gathered}
$$

where $-0^{*}$ represents the 0 -termination, $-\mathrm{OH}^{*}$ represents the $\mathrm{OH}$-termination and $-\mathrm{Fe}^{*}$ is the Fe-termination. In these equations, the Fe-termination is the reactant and is therefore considered as the reference in the calculation of reaction free energies. Here, the reaction free energy $\Delta G$ is calculated as $\Delta G=$ $\Sigma G_{\text {product }}-\Sigma G_{\text {reactant, }}$ with the free energies of reactants and products $G=G_{0}+G_{\mathrm{U}}+G_{\mathrm{pH}}$, and $G_{0}=1.98 \mathrm{eV}+E_{\mathrm{i}}+\mathrm{ZPE}_{\mathrm{i}}-\mathrm{TS}_{\mathrm{i}}, E_{\mathrm{i}}$ is the electronic energy directly from the DFT calculation, $G_{\mathrm{U}}=\mathrm{eU}$ and therefore depends on the applied potentials, and $G_{\mathrm{pH}}$ is the $\mathrm{pH}$ correction to the free energy. As shown by the free energy differences in (i) and (ii), the oxidation of the Fe-terminated surface under the alkaline conditions is spontaneous, making the OH-termination the most stable without applying an external potential. Of course, an applied external potential could alter the relative stability of different terminations [48].

The above reactions can also be used to include the effect of excessive $\mathrm{OH}^{-}$. Similar to treating the effect of proton concen- tration, a correction of $2.303 k_{\mathrm{B}} T(14-\mathrm{pH})$ can be derived based on the Nernst equation. At $\mathrm{pH}=14$, this correction would be zero.

\subsection{The OER Mechanism}

Oxygen formation on different surface terminations of $\mathrm{FeOOH}$ (010) may undergo different pathways. On OH-termination, the reaction could occur through two different pathways, i.e. involving one or two surface $\mathrm{OH}$ groups, as shown below:

Pathway 1 (one $-\mathrm{OH}^{*}$ )

$$
\begin{aligned}
& -\mathrm{OH}^{*}+\mathrm{OH}^{-}+\mathrm{h}^{+} \rightarrow \mathrm{H}_{2} \mathrm{O}+-\mathrm{O}^{*} \\
& -\mathrm{O}^{*}+\mathrm{OH}^{-}+\mathrm{h}^{+} \rightarrow-\mathrm{OOH}^{*} \\
& -\mathrm{OOH}^{*}+\mathrm{OH}^{-}+\mathrm{h}^{+} \rightarrow-\mathrm{OO}^{*}+\mathrm{H}_{2} \mathrm{O} \\
& -\mathrm{OO}^{*} \rightarrow \mathrm{Ov}+\mathrm{O}_{2}(\mathrm{~g}) \\
& \mathrm{Ov}+\mathrm{OH}^{-}+\mathrm{h}^{+} \rightarrow-\mathrm{OH}^{*}
\end{aligned}
$$

Pathway 2 (two $-\mathrm{OH}^{*} \mathrm{~s}$ ):

$$
\begin{aligned}
& 2-\mathrm{OH}^{*}+\mathrm{OH}^{-}+\mathrm{h}^{+} \rightarrow-\mathrm{OOH}^{*}+\mathrm{H}_{2} \mathrm{O} \\
& -\mathrm{OOH}^{*}+\mathrm{OH}^{-}+\mathrm{h}^{+} \rightarrow-\mathrm{OO}^{*}+\mathrm{H}_{2} \mathrm{O} \\
& -\mathrm{OO}^{*} \rightarrow 2 \mathrm{Ov}+\mathrm{O}_{2}(\mathrm{~g}) \\
& 2 \mathrm{Ov}+\mathrm{OH}^{-}+\mathrm{h}^{+} \rightarrow\left(-\mathrm{OH}^{*}+\mathrm{Ov}\right) \\
& \left(-\mathrm{OH}^{*}+\mathrm{Ov}\right)+\mathrm{OH}^{-}+\mathrm{h}^{+} \rightarrow 2-\mathrm{OH}^{*}
\end{aligned}
$$

on the O-termination, oxygen formation will occur through the following steps:

Pathway 1 (one $-0^{*}$ ):

$$
\begin{aligned}
& -\mathrm{O}^{*}+\mathrm{OH}^{-}+\mathrm{h}^{+} \rightarrow-\mathrm{OOH}^{*} \\
& -\mathrm{OOH}^{*}+\mathrm{OH}^{-}+\mathrm{h}^{+} \rightarrow-\mathrm{OO}^{*}+\mathrm{H}_{2} \mathrm{O} \\
& -\mathrm{OO}^{*} \rightarrow \mathrm{O}_{2}(\mathrm{~g})+\mathrm{Ov} \\
& \mathrm{Ov}+\mathrm{OH}^{-}+\mathrm{h}^{+} \rightarrow-\mathrm{H}^{*} \\
& -\mathrm{H}^{*}+\mathrm{OH}^{-}+\mathrm{h}^{+} \rightarrow-\mathrm{O}^{*}+\mathrm{H}_{2} \mathrm{O}
\end{aligned}
$$

Pathway 2 (two $-0^{*} \mathrm{~s}$ ):

$$
\begin{aligned}
& 2-\mathrm{O}^{*} \rightarrow \mathrm{O}_{2}(\mathrm{~g})+2 \mathrm{Ov} \\
& 2 \mathrm{Ov}+\mathrm{OH}^{-}+\mathrm{h}^{+} \rightarrow\left(-\mathrm{H}^{*}+\mathrm{Ov}\right) \\
& \left(-\mathrm{H}^{*}+\mathrm{Ov}\right)+\mathrm{OH}^{-}+\mathrm{h}^{+} \rightarrow\left(-\mathrm{O}^{*}+\mathrm{Ov}\right)+\mathrm{H}_{2} \mathrm{O} \\
& \left(-\mathrm{O}^{*}+\mathrm{Ov}\right)+\mathrm{OH}^{-}+\mathrm{h}^{+} \rightarrow\left(-\mathrm{H}^{*}+-\mathrm{O}^{*}\right) \\
& \left(-\mathrm{H}^{*}+-\mathrm{O}^{*}\right)+\mathrm{OH}^{-}+\mathrm{h}^{+} \rightarrow 2-\mathrm{O}^{*}+\mathrm{H}_{2} \mathrm{O}
\end{aligned}
$$

on the Fe-termination of $\mathrm{FeOOH}(010)$, no exposed surface oxygen could participate in the formation of the oxygen molecule. Consequently, oxygen-containing species can only form from reacting with $\mathrm{OH}^{-}$through the following steps:

Pathway:

$$
\begin{aligned}
& *+\mathrm{OH}^{-}+\mathrm{h}^{+} \rightarrow-\mathrm{OH}^{*} \\
& -\mathrm{OH}^{*}+\mathrm{OH}^{-}+\mathrm{h}^{+} \rightarrow \mathrm{H}_{2} \mathrm{O}+-\mathrm{O}^{*} \\
& -\mathrm{O}^{*}+\mathrm{OH}^{-}+\mathrm{h}^{+} \rightarrow-\mathrm{OOH}^{*} \\
& -\mathrm{OOH}^{*}+\mathrm{OH}^{-}+\mathrm{h}^{+} \rightarrow \mathrm{H}_{2} \mathrm{O}+-\mathrm{OO}^{*} \\
& -\mathrm{OO}^{*} \rightarrow \mathrm{O}_{2}(\mathrm{~g})+*
\end{aligned}
$$

In our calculation, we use neutral $\mathrm{OH}$ as a reactant instead of the $\left(\mathrm{OH}^{-}+\mathrm{h}^{+}\right)$pair directly. The neutral $\mathrm{OH}$ can be considered as $\mathrm{OH}^{-}$being oxidized by a hole $\left(\mathrm{h}^{+}\right)$. In the free energy calculations, we used a correction of $1.98 \mathrm{eV}$ determined in the previous section for steps involving $\mathrm{OH}$ to account for its formation from $\mathrm{OH}^{-}+\mathrm{h}^{+}$. Consequently, the reaction Gibbs free energy for each OER step is calculated by following the same procedures of determining the reaction Gibbs energy of reaction (1) and (2), i.e. $\Delta G=\Delta G_{0}+\Delta G_{\mathrm{U}}+\Delta G_{\mathrm{pH}}$, with $\Delta G_{0}=1.98 \mathrm{eV}+\Delta E_{\mathrm{i}}+\Delta \mathrm{ZPE}_{\mathrm{i}}$ - $T \Delta S_{\mathrm{i}}$, where $\Delta \mathrm{ZPE}$ and $\Delta S_{\mathrm{i}}$ are calculated from frequencies of 
the system. We note that the steps without involving the $\left(\mathrm{OH}^{-}+\right.$ $\mathrm{h}^{+}$) pair, including reactions (6), (10), (15), (18) and (27), will not be affected by the applied electrode potentials. The theoretical overpotential $\eta$ for the steps involving $\mathrm{OH}^{-}+\mathrm{h}^{+}$is defined as $[\Delta G / \mathrm{e}-1.23 \mathrm{~V}]$. The largest value of $\eta$ corresponds to the thermodynamic potential-limiting step in the OER process.

\subsection{OER on $\mathrm{FeOOH}(010)$}

Based on the OER mechanism on each surface termination discussed above, we optimized the structures of the intermediates and determined the reaction free energies and overpotentials of all the pathways and listed the results in Table 1 and plotted in Fig. 3(a). On the OH-termination of FeOOH (010), we considered two possible OER pathways, as shown in Fig. 3(a). Pathway 1 involves only one surface $\mathrm{OH}$ group. Along this pathway, $\mathrm{OH}$ from $\left(\mathrm{OH}^{-}+\mathrm{h}^{+}\right)$reacts with the surface $-\mathrm{OH}^{*}$ group, forming one water molecule and leaving a surface $-0^{*}$. This step, i.e. extraction of the first surface proton by $\left(\mathrm{OH}^{-}+\mathrm{h}^{+}\right)$ to form water, is the potential-limiting step, with an overpotential of $2.54 \mathrm{~V}$. The resulting surface $-0^{*}$ can react further with additional $\left(\mathrm{OH}^{-}+\mathrm{h}^{+}\right)$, forming the surface $-\mathrm{OOH}^{*}$ species. The $-\mathrm{OOH}^{*}$ species continues to react with $\left(\mathrm{OH}^{-}+\mathrm{h}^{+}\right)$, leading to the $-00^{*}$ species and releasing a second water molecule. The $-00^{*}$ species would desorb as oxygen molecule, leaving a surface oxygen vacancy and exposing an $\mathrm{Fe}$ site. The oxygen vacancy can be replenished by reacting with $\left(\mathrm{OH}^{-}+\mathrm{h}^{+}\right)$, returning the surface to its original state. The intermediates involved in this pathway are depicted in Fig. 3(a). The reaction energies and overpotential for each step of pathway 1 are summarized in Table 1 and plotted in Fig. 3(d).

Pathway 2 of Fig. 3(a) on the OH-termination of $\mathrm{FeOOH}$ (010) involves two surface $-\mathrm{OH}^{*}$ groups. Following this pathway, the $\left(\mathrm{OH}^{-}+\mathrm{h}^{+}\right)$reacts with the surface $-\mathrm{OH}^{*}$ groups to form a water molecule and leaves $-0^{*}$ on the surface. The $-0^{*}$ can then combine with the neighboring $-\mathrm{OH}^{*}$ to form $-\mathrm{OOH}^{*}$. Similar to the pathway involving one $-\mathrm{OH}^{*}$, the surface $-\mathrm{OOH}^{*}$ continues to react with $\left(\mathrm{OH}^{-}+\mathrm{h}^{+}\right)$, forming $-\mathrm{OO}^{*}$ and releasing

\section{Table 1}

The calculated free energies of the OER intermediates and overpotential of the elementary step on the $\mathrm{OH}-, \mathrm{O}-$ and $\mathrm{Fe}$-termination of FeOOH (010). Also listed are the net charges of the Fe atoms involved in OER.

\begin{tabular}{|c|c|c|c|c|c|c|}
\hline $\mathrm{N}$ & Surface group & Reaction & $\Delta G_{\mathrm{o}}(\mathrm{eV})$ & $\eta(V)$ & Net charge of $\mathrm{Fe} 1\left(\mathrm{e}^{-}\right)$ & Net charge of $\mathrm{Fe} 2\left(\mathrm{e}^{-}\right)$ \\
\hline
\end{tabular}

$\begin{array}{lc} & -\mathrm{OH}^{*} \\ 3 & -\mathrm{O}^{*} \\ 4 & -00 \mathrm{H}^{*} \\ 5 & -00^{*} \\ 6 & \mathrm{Ov} \\ 7 & \end{array}$

$\begin{array}{lc} & 2-\mathrm{OH}^{*} \\ 8 & -00 H^{*} \\ 9 & -00^{*} \\ 10 & 2 \mathrm{Ov} \\ 11 & -\mathrm{OH}^{*}+\mathrm{Ov} \\ 12 & \end{array}$

$-0^{*}$

$-\mathrm{OOH}^{*}$

$-00^{*}$

Ov

$-\mathrm{H}^{*}$

$\begin{array}{cc}23 & \mathrm{OH}^{*} \\ 24 & \mathrm{O}^{*} \\ 25 & \mathrm{OOH}^{*} \\ 26 & \mathrm{OO}^{*}\end{array}$

$\begin{array}{ccc}-\mathrm{OH}^{*}+\mathrm{OH}^{-}+\mathrm{h}^{+} \rightarrow \mathrm{H}_{2} \mathrm{O}+-\mathrm{O}^{*} & - & - \\ -\mathrm{O}^{*}+\mathrm{OH}^{-}+\mathrm{h}^{+} \rightarrow-\mathrm{OOH}^{*} & 3.77 & 2.54 \\ -\mathrm{OOH}^{*}+\mathrm{OH}^{-}+\mathrm{h}^{+} \rightarrow-\mathrm{OO}^{*}+\mathrm{H}_{2} \mathrm{O} & -0.92 & -2.15 \\ -\mathrm{OO}^{*} \rightarrow \mathrm{Ov}+\mathrm{O}_{2}(\mathrm{~g}) & -1.39 & -2.62 \\ \mathrm{Ov}+\mathrm{OH}^{-}+\mathrm{h}^{+} \rightarrow-\mathrm{OH}^{*} & -1.24 & -\end{array}$

$\mathrm{OH}$-termination with two surface $\mathrm{OH}^{*} \mathrm{~s}$

$$
\begin{array}{crc}
2-\mathrm{OH}^{*}+\mathrm{OH}^{-}+\mathrm{h}^{+} \rightarrow-\mathrm{OOH}^{*}+\mathrm{H}_{2} \mathrm{O} & \multicolumn{1}{c}{} & 1.33 \\
-\mathrm{OOH}^{*}+\mathrm{OH}^{-}+\mathrm{h}^{+} \rightarrow-\mathrm{OO}^{*}+\mathrm{H}_{2} \mathrm{O} & -0.36 & -1.59 \\
-\mathrm{OO}^{*} \rightarrow 2 \mathrm{Ov}+\mathrm{O}_{2}(\mathrm{~g}) & 0.71 & - \\
2 \mathrm{Ov}+\mathrm{OH}^{-}+\mathrm{h}^{+} \rightarrow\left(-\mathrm{OH}^{*}+\mathrm{Ov}\right) & -1.19 & -2.42 \\
\left(-\mathrm{OH}^{*}+\mathrm{Ov}\right)+\mathrm{OH}^{-}+\mathrm{h}^{+} \rightarrow 2-\mathrm{OH}^{*} & -1.24 & -2.47
\end{array}
$$

0 -termination with one surface $0^{*}$

$$
\begin{array}{ccc}
-\mathrm{O}^{*}+\mathrm{OH}^{-}+\mathrm{h}^{+} \rightarrow-\mathrm{OOH}^{*} & - & - \\
-\mathrm{OOH}^{*}+\mathrm{OH}^{-}+\mathrm{h}^{+} \rightarrow-\mathrm{OO}^{*}+\mathrm{H}_{2} \mathrm{O} & -0.12 & -1.35 \\
-\mathrm{OO}^{*} \rightarrow \mathrm{O}_{2}(\mathrm{~g})+\mathrm{Ov} & -0.36 & -1.59 \\
\mathrm{Ov}+\mathrm{OH}^{-}+\mathrm{h}^{+} \rightarrow-\mathrm{H}^{*} & -0.12 & - \\
-\mathrm{H}^{*}+\mathrm{OH}^{-}+\mathrm{h}^{+} \rightarrow-\mathrm{O}^{*}+\mathrm{H}_{2} \mathrm{O} & -0.36 & -1.59
\end{array}
$$

O-termination with two surface $0^{*} \mathrm{~s}$

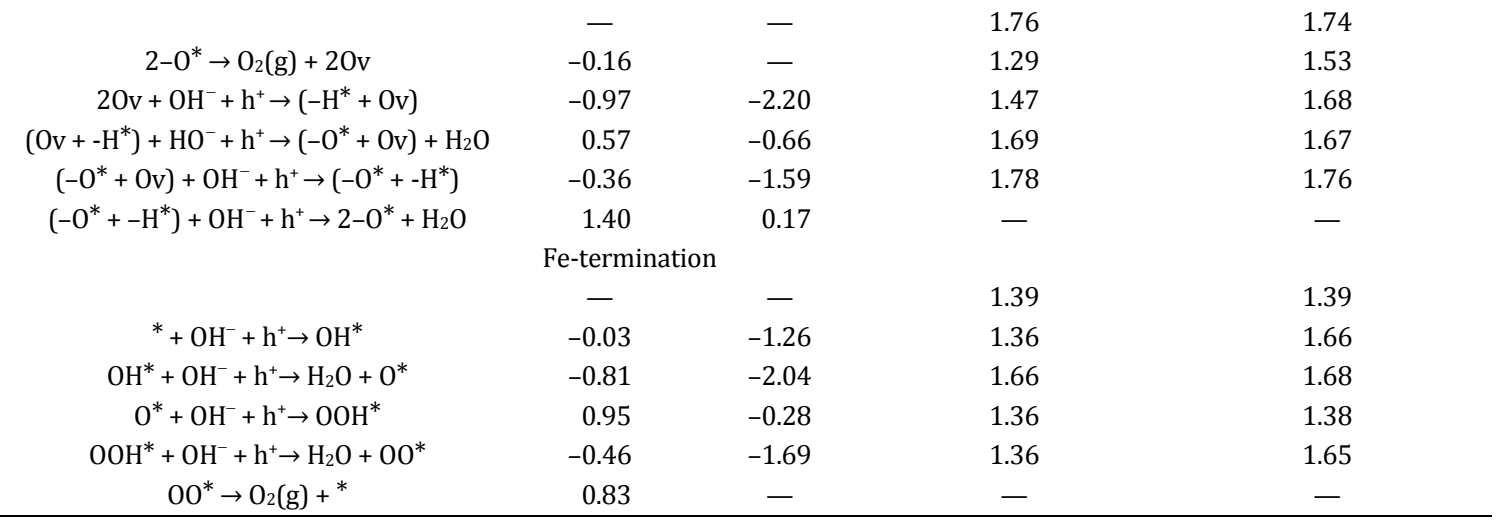


(a) $\mathrm{OH}$-termination $\left(4 \mathrm{OH}^{\star}\right)$

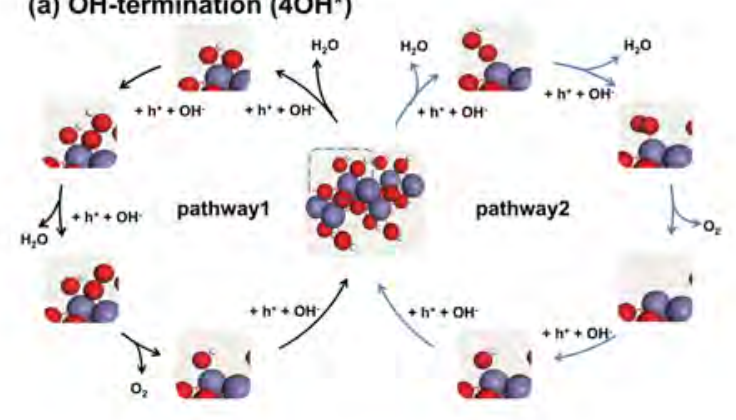

(b) O-termination (40*)

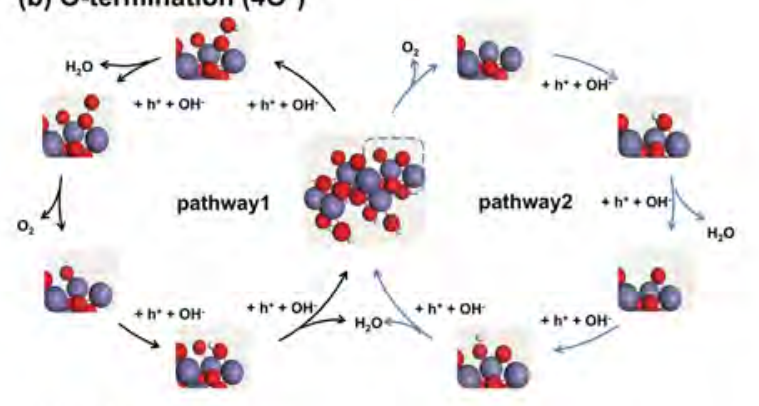

(c) Fe-termination $\left(^{*}\right)$

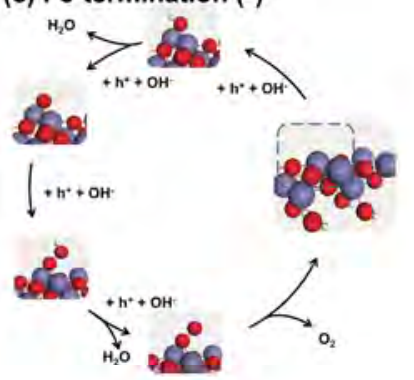

(d) OH-termination

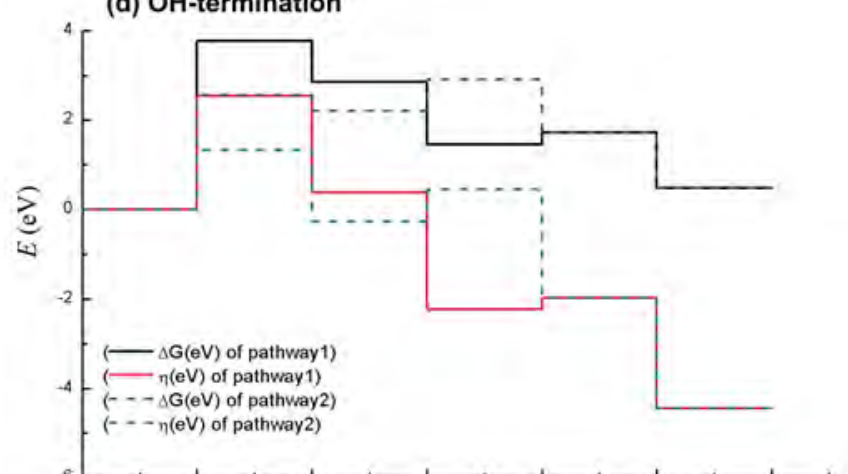

(e) O-termination

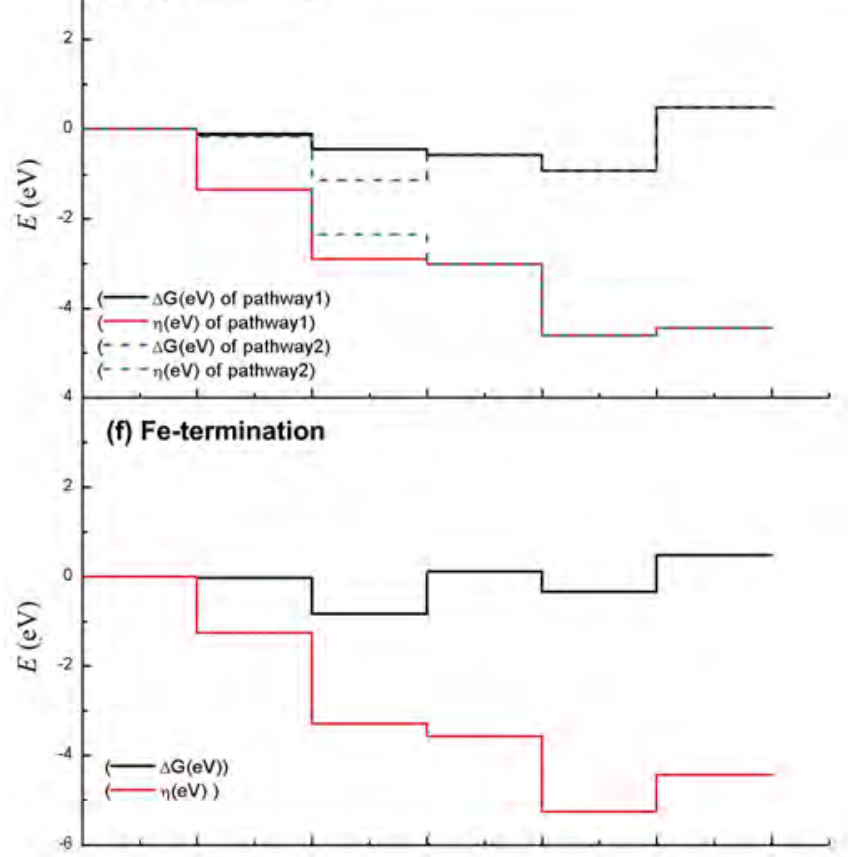

Fig. 3. Possible pathways for oxygen formation on the (a) $\mathrm{OH}-$, (b) $\mathrm{O}-$, and (c) Fe-termination of the $\mathrm{FeOOH} \mathrm{(010)} \mathrm{surface} \mathrm{and} \mathrm{the} \mathrm{corresponding} \mathrm{en-}$ ergy diagrams (d, e, f). Blue spheres represent the Fe atoms, red the $\mathrm{O}$ atoms and white the $\mathrm{H}$ atoms.

a second water molecule. The $-00^{*}$ species desorbs as an oxygen molecule and leaves two surface oxygen vacancies, which can be healed by reacting with two $\left(\mathrm{OH}^{-}+\mathrm{h}^{+}\right)$in a sequential order. The first step, with an overpotential of $1.33 \mathrm{~V}$, is the potential-limiting step for this pathway. Clearly, this step also involves the bond breaking process of the surface $\mathrm{OH}$ group. The $\mathrm{O}_{2}$ desorption step has the second highest reaction free energy of $0.71 \mathrm{eV}$, and the following steps are all spontaneous under an electrode potential of $1.23 \mathrm{~V}$. These results show that breaking the surface $\mathrm{O}-\mathrm{H}$ bond of the surface $\mathrm{OH}^{*}$ on the FeOOH(010) surface is the potential-limiting step on the OH-terminated surface for both pathways, and pathway 2 required a lower overpotential compared with pathway 1 , as shown in Fig. 3(d).

Two possible OER pathways, i.e. involving either one or two surface $\mathrm{O}$ atoms, on the O-terminated $\mathrm{FeOOH} \mathrm{(010)} \mathrm{surface} \mathrm{are}$ also examined, as shown in Fig. 3(b). For the pathway involving one surface $-0^{*}$ (pathway 1 in Fig. $3(b)$ ), the $\left(\mathrm{OH}^{-}+\mathrm{h}^{+}\right)$first reacts with the surface $-0^{*}$ to form $-\mathrm{OOH}^{*}$. This is followed by $-\mathrm{OOH}^{*}$ reacting with a second $\left(\mathrm{OH}^{-}+\mathrm{h}^{+}\right)$pair, forming a water molecule and leaving $-\mathrm{OO}^{*}$ on the surface. The $-\mathrm{OO}^{*}$ species desorbs from the surface in the form of an oxygen molecule, resulting in an oxygen vacancy on the surface, which exposes a Fe site. A new $\left(\mathrm{OH}^{-}+\mathrm{h}^{+}\right)$pair binds the exposed Fe site and forms a surface $\mathrm{OH}^{*}$ species, and this $\mathrm{OH}^{*}$ species can further react with $\left(\mathrm{OH}^{-}+\mathrm{h}^{+}\right)$to form one water molecule by breaking the $\mathrm{H}-\mathrm{O}$ bond. This is the potential-limiting step along this pathway with a small overpotential of $0.17 \mathrm{~V}$. As shown in Table 1 , the overpotentials $\eta$ of other elementary steps are all negative. The free energy changes and the overpotentials of each step were plotted in Fig. 3(e).

For the pathway involving two surface oxygen atoms on the 0-terminated surface (Fig. 3(b), pathway 2), two surface oxygen atoms first combine to form an $\mathrm{O}_{2}$ molecule, leaving two oxygen vacancies, and in the meantime, exposing two Fe sites. The two Fe sites can react with two $\left(\mathrm{OH}^{-}+\mathrm{h}^{+}\right)$pairs to heal the 
surface by forming two surface $-\mathrm{OH}^{*}$ s. This will bring the surface back to the $-\mathrm{OH}^{*}$ terminated surface. The $\eta$ value for breaking one of the $\mathrm{O}-\mathrm{H}$ bond of the newly formed $-\mathrm{OH}^{*} \mathrm{~S}$ under the standard OER potential is negative $(-0.66 \mathrm{~V})$, while for breaking the second $\mathrm{O}-\mathrm{H}$, the overpotential is only $0.17 \mathrm{~V}$, same as pathway 1 . The difference in the overpotentials for the two $\mathrm{O}-\mathrm{H}$ bond breaking steps can be attributed to the existence of the oxygen vacancy. The oxygen vacancy promotes the breaking of the $\mathrm{O}-\mathrm{H}$ bond of the first $\mathrm{OH}$ group. For O-termination, the overpotentials of the limit step for both mechanisms are the same and are much lower than that on $\mathrm{OH}$-termination. The results indicate that the $\mathrm{O}$-termination has a higher OER activity than the OH-termination. We note that the breaking the $\mathrm{O}-\mathrm{H}$ bond is also the potential-limiting step of OER on the 0-terminated surface, as shown in Fig. 3(e).

On the Fe-terminated surface, the $\left(\mathrm{OH}^{-}+\mathrm{h}^{+}\right)$pairs adsorb first on the surface Fe sites before the oxygen formation steps could take place. The reaction with the $\left(\mathrm{OH}^{-}+\mathrm{h}^{+}\right)$pairs forms $-\mathrm{OH}^{*}$, which then transforms to $-\mathrm{O}^{*},-\mathrm{OOH}^{*}$ and $-\mathrm{OO}^{*}$ following a stepwise process as shown in Fig. 3(c). The $-00^{*}$ would desorb from the surface in the form of $\mathrm{O}_{2}$. All the elementary steps are energetically favorable under the standard OER potential except for the $\mathrm{O}_{2}$ desorption step, which has a reaction free energy of $0.83 \mathrm{eV}$, as shown in Table 1 and Fig. 3(f).

In summary, the (010) surface of $\mathrm{FeOOH}$ favors the OH-termination thermodynamically without applied potentials. To activate the surface for OER, an overpotential of $2.54 \mathrm{~V}$ has to be applied to break the first $\mathrm{O}-\mathrm{H}$ bond, resulting in $-\mathrm{O}^{*}$, which will continue to react under such a potential, finally forming the $\mathrm{O}_{2}$ molecule. Desorption of the $00^{*}$ species to form gas phase $\mathrm{O}_{2}$ molecule is not spontaneous under the standard condition. Under operating condition of the electrolyzer, the electrode surface would be under a constant transformation due to $\mathrm{OH}$ adsorption and oxygen formation. A clearer picture developed from the above analysis of the elementary steps is that an external potential is needed for the $\mathrm{OH}$ - and $\mathrm{O}$ - terminated surfaces to become activated for OER. The formation and turn-over of the surface oxygen species are the integral steps of the reaction mechanism, in analogue to the Mars-van Krevelen mechanism in heterogeneous catalysis $[49,50]$. The results also point to the dynamical nature of the surface structure in the reaction process. The structural flexibility allowed by the oxyhydroxides and perovskite oxides made them highly active for catalyzing OER.

In addition to the free energy variations along each reaction pathway, the charge transfer/redistribution would help to shed light on the redox process. Therefore, we performed Bader charge analysis along each reaction pathway on all three surface terminations with the possible intermediates. For convenience, we used bulk hydroxides as the reference. As shown in
Table 2, the Bader charges of the Fe atom in bulk $\mathrm{Fe}(\mathrm{OH})_{2}$ and $\mathrm{FeOOH}$ phases are $1.36 \mathrm{e}^{-}$and $1.82 \mathrm{e}^{-}$, respectively. Clearly, the Bader charge values reflect qualitatively the relative level of oxidation of $\mathrm{Fe}$ in these oxides. We note these values differ from the corresponding formal charge values significantly. As a reference, we also listed the Bader charges of the surface Fe atom directly involved in the reaction on each surface termination in Table 2. Clearly, the surface Fe atoms in $\mathrm{OH}$ - and $\mathrm{O}$ - terminated surfaces are reduced slightly compared with the $\mathrm{Fe}$ atoms in bulk FeOOH. The Fe atom in the Fe-terminated surface is significantly reduced and its net charge is very close to Fe in bulk $\mathrm{Fe}(\mathrm{OH})_{2}$.

Details of the Bader charge variations of $\mathrm{Fe}$ in all three terminations along each OER pathway are shown in Table 1 . We focused on the two Fe atoms directly binding the adsorbed surface intermediates (Fe in the dashed box in Fig. 3), which are the active sites for OER. Generally, the Fe atoms are oxidized by reacting with $\mathrm{OH}$, either in the form of $\mathrm{H}$ removal or $00^{*}$ formation, and reduced by releasing $\mathrm{O}_{2}$. Along pathway of left cycle on the $\mathrm{OH}$-terminated surface, the process starts with Fe reduction by losing one $\mathrm{H}$. The Bader charges on the two $\mathrm{Fe}$ atoms indicate that the two Fe atoms were not reduced equally. The formation of $-\mathrm{OOH}^{*}$ by further reacting the $\mathrm{O}^{*}$ site with another $\mathrm{OH}$ results in one Fe being reduced while another oxidized. This is consistent with the adsorption structure that the $-\mathrm{OOH}^{*}$ is tilted toward the oxidized $\mathrm{Fe}$ atom. Losing $\mathrm{H}$ from $\mathrm{OOH}^{*}$ further oxidizes the binding $\mathrm{Fe}$ site while leaving the other unchanged. Desorption of $\mathrm{O}_{2}$ causes reduction of both $\mathrm{Fe}$ atoms, with the $\mathrm{Fe}$ atom binding $0^{*}$ having a larger net charge change. Similar redox processes but with different order of appearance could be identified in other cycles.

\section{Conclusions}

In this work, we studied OER mechanism on the three terminations of the FeOOH (010) surface based on the results of the DFT + U calculations. We first established chemical potential of the $\left(\mathrm{OH}^{-}+\mathrm{h}^{+}\right)$pair to include the $\mathrm{OH}^{-}$anion in the reaction pathway. The inclusion of the $\left(\mathrm{OH}^{-}+\mathrm{h}^{+}\right)$pair allows us to account for the anodic OER process under the alkaline conditions. We then analyzed the possible reaction pathways on each surface termination individually. On the surface with $\mathrm{OH}$ - and $\mathrm{O}$ - terminations, the $\mathrm{O}_{2}$ molecule may form from either $\mathrm{OH}$ reacting with the surface oxygen species or combination of the two surface oxygen species. The potential-limiting steps of the oxygen evolution with different surface terminations were determined by following the free-energy change of each elementary step along each pathway. The Fe-terminated surface is intrinsically active for OER but is thermodynamically unfavorable. External potential helps the turn-over of $\mathrm{OH}^{-}$under alka-

Table 2

The net Bader charge of $\mathrm{Fe}(\mathrm{a})$ in bulk $\mathrm{FeOOH}$ and $\mathrm{Fe}(\mathrm{OH})_{2}$, (b) the first layer of the clean $\mathrm{OH}-, \mathrm{O}$ - and Fe- termination of $\mathrm{FeOOH}(010)$.

\begin{tabular}{|c|c|c|c|c|c|}
\hline \multirow{2}{*}{ Item } & \multirow{2}{*}{$\mathrm{FeOOH}^{\mathrm{a}}$} & \multirow{2}{*}{$\mathrm{Fe}(\mathrm{OH})_{2}{ }^{\mathrm{a}}$} & \multicolumn{3}{|c|}{ FeOOH (010) with different terminations } \\
\hline & & & $\mathrm{OH}^{-\mathrm{b}}$ & $0-^{b}$ & $\mathrm{Fe}^{\mathrm{b}}$ \\
\hline Net charge of Fe in bulk $\left(\mathrm{e}^{-}\right)$ & 1.82 & 1.36 & - & - & - \\
\hline Net charge of the 1st layer $\mathrm{Fe}\left(\mathrm{e}^{-}\right)$ & - & - & 1.78 & 1.76 & 1.39 \\
\hline
\end{tabular}


line conditions and refreshes the surface Fe sites. Our results show that oxygen formation requires recreating the surface $\mathrm{Fe}$ sites, and consequently, the condition that favors partially exposed Fe sites will promote formation of oxygen.

\section{Acknowledgment}

We acknowledge the support of by the Chemical, Biological, Environmental, and Transport Systems (CBET) program of US National Science Foundation (CBET-1438440). Computation has been performed in part using the Molecular Science Computing Facility in the William R. Wiley Environmental Molecular Sciences Laboratory (EMSL), which is a U.S. Department of Energy national scientific user facility located at Pacific Northwest National Laboratory (PNNL) in Richland, Washington.

\section{References}

[1] N. S. Lewis, D. G. Nocera, Proceedings of the National Academy of Sciences of U.S.A., 2006, 103, 15729-15735.

[2] D. Gust, T. A. Moore, A. L. Moore, Acc. Chem. Res., 2009, 42, 1890-1898.

[3] Z. G. Yang, J. L. Zhang, M. C. W. Kintner-Meyer, X. C. Lu, D. Choi, J. P. Lemmon, J. Liu, Chem. Rev., 2011, 111, 3577-3613.

[4] I. Katsounaros, S. Cherevko, A. R. Zeradjanin, K. J. J. Mayrhofer, Angew. Chem. Int. Ed., 2014, 53, 102-121.

[5] M. G. Walter, E. L. Warren, J. R. McKone, S. W. Boettcher, Q. X. Mi, E. A. Santori, N. S. Lewis, Chem. Rev., 2010, 110, 6446-6473.

[6] J. Suntivich, K. J. May, H. A. Gasteiger, J. B. Goodenough, Y. Shao-Horn, Science, 2011, 334, 1383-1385.

[7] T. Audichon, T. W. Napporn, C. Canaff, C. Morais, C. Comminges, K. B. Kokoh, J. Phys. Chem. C, 2016, 120, 2562-2573.

[8] A. Minguzzi, O. Lugaresi, E. Achilli, C. Locatelli, A. Vertova, P. Ghigna, S. Rondinini, Chem. Sci., 2014, 5, 3591-3597.

[9] Y. H. Fang, Z. P. Liu, J. Am. Chem. Soc., 2010, 132, 18214-18222.

[10] W. D. Chemelewski, J. R. Rosenstock, C. B. Mullins, J. Mater. Chem. A, 2014, 2, 14957-14962.

[11] W. D. Chemelewski, H. C. Lee, J. F. Lin, A. J. Bard, C. B. Mullins, J. Am.
Chem. Soc., 2014, 136, 2843-2850.

[12] J. A. Seabold, K. S. Choi, J. Am. Chem. Soc., 2012, 134, 2186-2192.

[13] T. W. Kim, K. S. Choi, Science, 2014, 343, 990-994.

[14] X. Q. Zhang, P. Klaver, R. van Santen, M. C. M. van de Sanden, A. Bieberle-Hutter, J. Phys. Chem. C, 2016, 120, 18201-18208.

[15] P. P. Patel, M. K. Datta, O. I. Velikokhatnyi, R. Kuruba, K. Damodaran, P. Jampani, B. Gattu, P. M. Shanthi, S. S. Damle, P. N. Kumta, Sci. Rep., 2016, 6, 28367.

[16] J. X. Feng, H. Xu, Y. T. Dong, S. H. Ye, Y. X. Tong, G. R. Li, Angew. Chem. Int. Ed., 2016, 55, 3694-3698.

[17] 0. Diaz-Morales, D. Ferrus-Suspedra, M. T. M. Koper, Chem. Sci., 2016, 7, 2639-2645.

[18] S. H. Zou, M. S. Burke, M. G. Kast, J. Fan, N. Danilovic, S. W. Boettcher, Chem. Mater., 2015, 27, 8011-8020.

[19] R. Pokhrel, M. K. Goetz, S. E. Shaner, X. X. Wu, S. S. Stahl, J. Am. Chem. Soc., 2015, 137, 8384-8387.

[20] R. Frydendal, M. Busch, N. B. Halck, E. A. Paoli, P. Krtil, I. Chorkendorff, J. Rossmeisl, ChemCatChem, 2015, 7, 149-154.

[21] D. Friebel, M. W. Louie, M. Bajdich, K. E. Sanwald, Y. Cai, A. M. Wise, M. J. Cheng, D. Sokaras, T. C. Weng, R. Alonso-Mori, R. C. Davis, J. R. Bargar, J. K. Norskov, A. Nilsson and A. T. Bell, J. Am. Chem. Soc., 2015, 137, 1305-1313.

[22] M. S. Burke, L. J. Enman, A. S. Batchellor, S. H. Zou, S. W. Boettcher, Chem. Mater., 2015, 27, 7549-7558.

[23] L. Trotochaud, S. L. Young, J. K. Ranney, S. W. Boettcher, J. Am. Chem. Soc., 2014, 136, 6744-6753.

[24] C. Du, X. G. Yang, M. T. Mayer, H. Hoyt, J. Xie, G. McMahon, G. Bischoping, D. W. Wang, Angew. Chem. Int. Ed., 2013, 52, 12692-12695.

[25] I. C. Man, H. Y. Su, F. Calle-Vallejo, H. A. Hansen, J. I. Martínez, N. G. Inoglu, J. Kitchin, T. F. Jaramillo, J. K. Nørskov, J. Rossmeisl, ChemCatChem, 2011, 3, 1159-1165.

[26] M. S. Burke, M. G. Kast, L. Trotochaud, A. M. Smith, S. W. Boettcher, J. Am. Chem. Soc., 2015, 137, 3638-3648.

[27] M. S. Burke, S. H. Zou, L. J. Enman, J. E. Kellon, C. A. Gabor, E. Pledger and S. W. Boettcher, J. Phys. Chem. Lett., 2015, 6, 3737-3742.

[28] Y. Matsumoto and E. Sato, Mater. Chem. Phys., 1986, 14, 397-426.

[29] J. Rossmeisl, Z. W. Qu, H. Zhu, G. J. Kroes and J. K. Nørskov, J. Electroanal. Chem., 2007, 607, 83-89.

\section{Graphical Abstract}

Chin. J. Catal., 2017, 38: 1621-1628 doi: 10.1016/S1872-2067(17)62760-8

\section{Mechanistic understanding on oxygen evolution reaction on $\gamma$-FeOOH (010) under alkaline condition based on DFT computational study}

Miru Tang, Qingfeng Ge*

Southern Illinois University, USA

Oxygen evolution mechanism on $\mathrm{FeOOH}(010)$ catalyst under the alkaline condition. The circled $\mathrm{OH}^{-}$represent hydroxide ions in solution. Blue sphere is $\mathrm{Fe}$, red $\mathrm{O}$ and white $\mathrm{H}$.

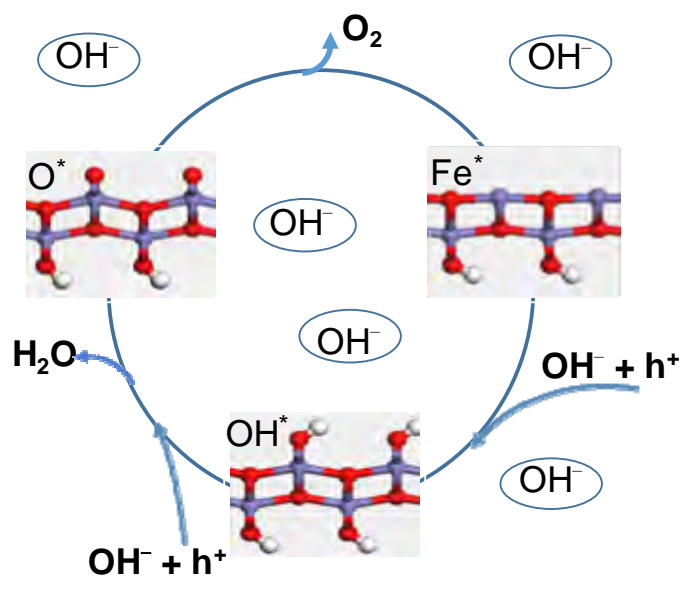


[30] J. Chen, Y. F. Li, P. Sit and A. Selloni, J. Am. Chem. Soc., 2013, 135, 18774-18777.

[31] R. L. Doyle, M. E. G. Lyons, Phys. Chem. Chem. Phys., 2013, 15, 5224-5237.

[32] G. L. Elizarova, L. G. Matvienko, V. L. Kuznetsov, D. I. Kochubey, V. N. Parmon, J. Mol. Catal. A, 1995, 103, 43-50.

[33] G. L. Elizarova, G. M. Zhidomirov, V. N. Parmon, Catal. Today, 2000, $58,71-88$.

[34] G. Kresse, J. Furthmuller, VASP, the Guide, http://cms.mpi.univie.ac.at/VASP/).

[35] G. Kresse, J. Hafner, Phys. Rev. B, 1993, 48, 13115-13118.

[36] J. P. Perdew, K. Burke and M. Ernzerhof, Phys. Rev. Lett., 1996, 77, 3865-3868.

[37] S. L. Dudarev, G. A. Botton, S. Y. Savrasov, C. J. Humphreys, A. P. Sutton, Phys. Rev. B, 1998, 57, 1505-1509.

[38] G. Kresse, D. Joubert, Phys. Rev. B, 1999, 59, 1758-1775.

[39] A. P. Zhukhlistov, Crystallogr. Rep., 2001, 46, 730-733.
[40] J. Rossmeisl, J. K. Nörskov, C. D. Taylor, M. J. Janik, M. Neurock, J. Phys. Chem. B, 2006, 110, 21833-21839.

[41] M. T. M. Koper, J. Electroanal. Chem., 2011, 660, 254-260.

[42] M. T. M. Koper, Chem. Sci., 2013, 4, 2710-2723.

[43] N. Jin, J. Y. Han, H. Wang, X. L. Zhu, Q. F. Ge, Int. J. Hydrogen Energy, 2015, 40, 5126-5134.

[44] C. N. Cui, J. Y. Han, X. L. Zhu, X. Liu, H. Wang, D. H. Mei, Q. F. Ge, J. Catal., 2016, 343, 257-265.

[45] C. N. Cui, H. Wang, X. L. Zhu, J. Y. Han, Q. F. Ge, Sci. China Chem., 2015, 58, 607-613.

[46] K. Otte, W. W. Schmahl, R. Pentcheva, J. Phys. Chem. C, 2013, 117, 15571-15582.

[47] K. Otte, W. W. Schmahl, R. Pentcheva, Surf. Sci., 2012, 606, 1623-1632.

[48] A. Hellman, R. G. S. Pala, J. Phys. Chem. C, 2011, 115, 12901-12907.

[49] C. Doornkamp, V. Ponec, J. Mol. Catal. A., 2000, 162, 32.

[50] J. Y. Ye, C. J. Liu, D. H. Mei, Q. F. Ge, ACS Catal., 2013, 3, 1296-1306.

\title{
DFT计算研究碱性条件下 $\gamma-F e O O H(010)$ 上氧析出反应机理
}

\author{
Miru Tang, Qingfeng Ge* \\ 南伊利诺伊大学化学与生物化学系, 卡本代尔 IL 62901,美国
}

摘要: 一个高效经济的氧析出反应(OER)催化剂是大范围应用太阳能转化能源的关键. 在众多有潜力的OER催化剂中, 金 属氢氧化物, 尤其是FeOOH表现出很高的OER活性. 我们采用DFT+U研究了 $\gamma$-FeOOH (010)表面上OER反应机理; 得到了 $\mathrm{OH}^{-}$和空穴对的化学势, 并将 $\mathrm{OH}^{-}$阴离子包含在反应机理中, 以此来说明碱性条件下阳极的OER过程. 随后分析了催化剂 中 OH-, O-和Fe-终止的表面上OER反应路径. 含有 $\mathrm{OH}-, \mathrm{O}$-终止的表面上, $\mathrm{O}_{2}$ 分子是通过 $\mathrm{OH}$ 与表面氧物种 $\left(-\mathrm{OH}^{*}\right.$ 和 $-\mathrm{O} *$ )反 应, 或二个表面氧物种相结合而形成的. 在 $\mathrm{Fe}$-终止的表面上, $\mathrm{O}_{2}$ 只能通过首先在 $\mathrm{Fe}$ 位上吸附 $\mathrm{OH}$ 而形成. 不同形式表面上 $\mathrm{O}_{2}$ 析出的化学势决定步骤取决于每个路径中基元步骤自由能的变化. 结果表明, $\mathrm{O}_{2}$ 的形成需要重建表面Fe位, 因此, 有利 于部分暴露 $\mathrm{Fe}$ 位的条件也将促进 $\mathrm{O}_{2}$ 的形成.

关键词: 水分解; 氧析出反应; $\mathrm{DFT}+\mathrm{U}$; 氢氧化铁

收稿日期: 2016-11-30. 接受日期: 2016-12-26. 出版日期: 2017-09-05.

*通讯联系人. 电子信箱: qge@chem.siu.edu

基金来源：美国国家科学基金会化学生物环境及传递系统项目 (CBET-1438440).

本文的英文电子版由Elsevier出版社在ScienceDirect上出版(http://www.sciencedirect.com/science/journal/18722067). 